\title{
Influence of first morning urine volume, fasting blood glucose and glycosylated hemoglobin on first morning urinary albumin concentration
}

M.B. Gomes, M.R. Lucchetti, M.F.R. Gonçalves, H. Gazzolla, T. Dimetz and H. Matos
Disciplina de Diabetes e Metabologia, Universidade do Estado do Rio de Janeiro, 20551-030 Rio de Janeiro, RJ, Brasil

\author{
Correspondence \\ M.B. Gomes \\ Disciplina de Diabetes e \\ Metabologia \\ Hospital Universitário \\ Pedro Ernesto \\ Av. 28 de Setembro, $77,3^{\circ}$ andar \\ 20551-030 Rio de Janeiro, RJ \\ Brasil \\ Research supported by CNPq \\ (No. 40644/93-2). M.R. Lucchetti \\ is the recipient of a CNPq \\ fellowship.
}

Received December 29, 1995 Accepted November 22, 1996

\begin{abstract}
The aim of the present study was to evaluate the effect of first morning urinary volume (collected on three different non-consecutive days), fasting blood glucose (determined on the first and third days of urine collection), and glycosylated hemoglobin (determined on the first and third days of urine collection) on the albumin concentration in first morning urine samples collected on three different days. We found 3.6\% asymptomatic bacteriuria in the urine samples; therefore, every urine sample must be tested to exclude infection. One hundred and fifty urine samples were provided by 50 IDDM patients aged $21.9 \pm 7(12-38)$ years with a disease duration of $6.8 \pm 5.8(0.4-31)$ years attending the Diabetes Clinic at the State University Hospital of Rio de Janeiro. There were no differences in albumin concentration ( 6.1 vs $5.8 \mathrm{vs} 6.2 \mu \mathrm{g} / \mathrm{ml} ; \mathrm{P}=\mathrm{NS}$ ) or urinary volume ( 222.5 vs $210 \mathrm{vs} 200 \mathrm{ml}$ ) between the three samples. In addition, there were no differences in fasting blood glucose $(181.9 \pm 93.6$ vs $194.6 \pm 104.7 \mathrm{mg} \% ; \mathrm{P}=\mathrm{NS})$ or glycosylated hemoglobin $(\mathrm{HbA} 1)(8.4$ \pm 1.3 vs $8.8 \pm 1.5 \%$; $\mathrm{P}=\mathrm{NS}$ ) between the first and third blood samples. Six patients (group 1) had a mean urinary albumin concentration of more than $20 \mu \mathrm{g} / \mathrm{ml}$ for the three urine samples. This group was compared with the 44 patients (group 2) with a mean urinary albumin concentration for the three urine samples of less than $20 \mu \mathrm{g} / \mathrm{ml}$. No difference was found between groups 1 and 2 in relation to fasting blood glucose $(207.1 \pm 71.7$ vs $187.6 \pm 84.6 \mathrm{mg} / \mathrm{dl}), \mathrm{HbA} 1(8.1 \pm 0.9 \mathrm{vs} 8.6 \pm 1.1 \%)$ or urinary volume [202 (48.3-435) vs 246 (77.3-683.3) ml]. Stepwise multiple regression analysis with albumin concentration of first morning urine samples as the dependent variable, and urinary volume, fasting blood glucose and glycosylated hemoglobin as independent variables, showed that only $12 \%(\mathrm{P}=0.01)$ of the albumin concentration could be accounted for by the independent effect of morning urine volume on the first day of urine collection. No urine samples showed a change in the cutoff level of 20 $\mu \mathrm{g} / \mathrm{ml}$ of albumin concentration as the result of volume. Fasting blood glucose and glycosylated hemoglobin did not influence the urinary albumin concentration. Considerable variability in urinary albumin concentration was found in the three morning urine samples with a mean intraindividual coefficient variation of $56 \%$. In conclusion, in the present study, urinary volume had a minimal, though not constant, effect on first morning urinary albumin concentration. Day-to-day metabolic and clinical control of IDDM patients, except probably for ketoacidosis, should not contraindicate microalbuminuria screening in first morning urine samples.
\end{abstract}

Key words

- Insulin-dependent

diabetes mellitus

- Microalbuminuria

- Glycosylated hemoglobin

- First morning urine 


\section{Introduction}

Diabetic nephropathy is the main cause of increased morbidity and mortality in type I (insulin-dependent) diabetes mellitus (IDDM), affecting at least one-third of young diabetic subjects (1). A urinary albumin excretion rate (AER) above normal levels (microalbuminuria) but as yet undetectable by standard laboratory methods seems to be an early predictor of the development of nephropathy (2). These observations have been used to formulate the concept of incipient nephropathy (3). Microalbuminuria is not only related to diagnosis of incipient nephropathy but is also important for the early prevention of overt nephropathy (4) and to predict mortality from cardiovascular disease (5). The present level of increased AER has been set at $20 \mu \mathrm{g} / \mathrm{min}$ or $30 \mu \mathrm{g} / \mathrm{min}$ in at least two consecutive urine collections, with the "timed $24 \mathrm{~h}$ " and "overnight" urine collections being currently proposed (3). However, for screening purposes, untimed collections are advantageous. Most studies have dealt with the usefulness of the albumin concentration or the albumin/creatinine ratio in a random or morning urine collection for first screening (6-9). However, urine volume and patient metabolic control could interfere with this measurement.

The aim of the present study was to determine the effect of first morning urine volume, fasting blood glucose and glycosylated hemoglobin $\left(\mathrm{HbA}_{1}\right)$ on albumin concentration in the first morning urine sample collected on three different non-consecutive days.

\section{Material and Methods}

One hundred and ninety-eight first morning urine samples were obtained on three different non-consecutive days from 50 insulin-dependent diabetic outpatients (22 males and 28 females) aged $21.9 \pm 7$ (12-38) years with a disease duration of $6.8 \pm 5.8$
(0.4-31) years attending the Diabetes Clinic at the State University Hospital of Rio de Janeiro and classified according to the $\mathrm{Na}-$ tional Diabetes Data Group (10). All urine samples were obtained from patients under a satisfactory clinical control without any clinical signs or symptoms of diabetes decompensation (polyuria, thirst, weight loss, etc.) or ketoacidosis and on a day-to-day activity level. All patients received written instructions about urine collection and were instructed to maintain their usual diet and physical activity.

All urine samples passed shortly after the patients got up in the morning were collected into a container without a preservative. The urine volume was recorded for these samples and aliquots were separated into glass tubes. On the same day, fresh urine samples were collected for urine culture at the hospital. A fasting blood sample was also obtained on the first and third days of urine collection for glucose and $\mathrm{HbA}_{1}$ determinations.

The urine samples were assayed for urinary albumin concentration within 7 days of storage at $4^{\circ} \mathrm{C}$ after centrifugation. Albumin concentration was measured by radioimmunoassay (Diagnostic Product Corporation, Los Angeles, CA). This assay had a sensitivity of $0.3 \mu \mathrm{g} / \mathrm{ml}$ and intra-assay and interassay coefficients of variation were $2.7 \%$ and $3.5 \%$, respectively.

Serum glucose was measured by the glucose oxidase method (Cobas-Mira Roche, Switzerland) and glycosylated hemoglobin by cation-exchange chromatography (Bayer Diagnostic, Germany; reference range, 4.5 to $8 \%$ ).

\section{Statistical analysis}

Since the albumin concentration in first morning urine samples has a skewed distribution, the Mann-Whitney U-test was used for comparisons between two independent samples and the Wilcoxon test for comparisons between two dependent samples. For 
comparison between two dependent groups with normally distributed data, the paired Student $t$-test was used. For comparison between more than two independent groups with normally distributed data, one-way ANOVA was used; otherwise the KruskalWallis test was performed. For comparison between dependent samples not normally distributed with more than two measures, the Friedman test was used. When performing stepwise multiple regression analysis the albumin values were log transformed and were the dependent variable. The independent variables were first morning urinary volume, fasting blood glucose and glycosylated hemoglobin. The analyses were performed using the Statistical Package for the Social Science (SPSS) and EPI INFO (version 6.0). Data are reported as mean $( \pm \mathrm{SD})$ for normally distributed data and median (range) for skewed data. A P value less than 0.05 was considered to be significant. Mean intraindividual coefficients of variation for first morning albumin concentration and volume were also calculated (11).

\section{Results}

All three urine samples were collected within six months. Considering the 198 urine specimens, $24.4 \%(\mathrm{~N}=48)$ had some level of bacteriuria, with $20.8 \%(\mathrm{~N}=41)$ having less than $100,000 / \mathrm{mm}^{3}$ but more than $50,000 /$ $\mathrm{mm}^{3}$ and $3.6 \%(\mathrm{~N}=7)$ having more than $100,000 / \mathrm{mm}^{3}$ of bacteriuria. These 48 urine samples were discarded. Therefore, only the results for 150 urine specimens were submitted to statistical analysis.

The mean intraindividual coefficients of variation for urinary volume and albumin concentration in the first morning urine between the three samples were $68.2 \%$ and $56 \%$, respectively. The laboratory data for urinary albumin, urinary volume, fasting blood glucose and $\mathrm{HbA}_{1}$ are shown in Table 1. No differences in albumin concentration or urinary volume were observed between the three samples. In addition, there were no differences in fasting blood glucose or $\mathrm{HbA}_{1}$ between the first and third blood samples. A total of six patients (group 1) had a mean urinary albumin concentration of over 20 $\mu \mathrm{g} / \mathrm{ml}$ for the three urine samples. This group was compared with the 44 patients (group 2) with a mean urinary albumin concentration for the three urine samples of less than 20 $\mu \mathrm{g} / \mathrm{ml}$. No difference was found between groups 1 and 2 in relation to fasting blood glucose $(207.1 \pm 71.7$ vs $187.6 \pm 84.6 \mathrm{mg} /$ dl), $\mathrm{HbA}_{1}(8.1 \pm 0.9 v s 8.6 \pm 1.1 \%)$ or urinary volume [202 (48.3-435) vs 246 (77.3-683.3) $\mathrm{ml}]$.

Stepwise multiple regression analysis with albumin concentration as the dependent variable and urinary volume, fasting blood glucose and $\mathrm{HbA}_{1}$ as independent variables was performed with the data obtained on the three different days of urine collection. Urinary volume in the first morning urine sample reached a significant level, whereas fasting blood glucose and $\mathrm{HbA}_{1}$ did not. Therefore, we performed a univariate analysis with albumin concentration as the dependent variable and urinary volume as the independent variable in all urine samples. These results are reported in Table 2. No urine sample with an albumin concentration above $20 \mu \mathrm{g} /$ $\mathrm{ml}$ showed a significant influence of the urinary volume.

Table 1 - First morning urine albumin concentration, volume, fasting blood glucose and $\mathrm{HbA}_{1}$ of $50 \mathrm{IDDM}$ patients.

Data for urinary albumin and first morning urine volume are reported as median (range) (Friedman test). The other data are reported as means \pm SD. There were no statistical differences between samples for any of the variables studied (Student t-test).

\begin{tabular}{lccc}
\hline Variables & \multicolumn{3}{c}{ Samples } \\
\cline { 2 - 4 } & First & Second & Third \\
\hline Urinary albumin $(\mu \mathrm{g} / \mathrm{ml})$ & $6.1(1-95)$ & $5.8(1.1-80)$ & $6.2(1.2-75)$ \\
Urine volume $(\mathrm{ml})$ & $222.5(27-910)$ & $210(5-1120)$ & $200(25-640)$ \\
Glucose $(\mathrm{mg} / \mathrm{dl})$ & $181.9 \pm 93.6$ & & $194.6 \pm 104.7$ \\
$\mathrm{HbA}_{1}(\%)$ & $8.4 \pm 1.3$ & & $8.8 \pm 1.5$
\end{tabular}


Table 2 - Univariate regression analysis of first morning urinary albumin concentration with first morning urine volume of 50 IDDM patients.

\begin{tabular}{lcccc}
\hline Urinary volume & \multicolumn{4}{c}{ First urinary albumin concentration } \\
\cline { 2 - 5 } & $\mathrm{R}^{2}$ & $\mathrm{~F}$ (ANOVA) & B Coefficient & P value \\
\hline First sample & 0.12 & 6.74 & $-6.83 \mathrm{E} 04$ & 0.01 \\
Second sample & 0.05 & 2.64 & $-3.8 \mathrm{E} 04$ & 0.1 \\
Third sample & 0.08 & 4.33 & $-5.9 \mathrm{E} 04$ & 0.04
\end{tabular}

\section{Discussion}

Early identification of microalbuminuria is considered to be clinically important although some relevant issues concerning the methodology remain unresolved as recently discussed in Ref. 3. This fact is very important because many reports have demonstrated that therapeutic intervention can delay the development of end stage renal disease (12). Therefore, the precise classification of diabetic patients with respect to microalbuminuria or normoalbuminuria is important clinically.

In the present study, although only 7 (3.6\%) urine samples presented bacteriuria more than $100,000 / \mathrm{mm}^{3}$, without any symptoms of urinary tract infection, we have discarded all urine samples with bacteriuria more than $50,000 / \mathrm{mm}^{3}$ because there are no studies about the correlation between the level of increase in microalbuminuria and the level of asymptomatic bacteriuria. No increase or a small increase in albumin concentration has been described in non-insulin-dependent diabetic patients or in the nondiabetic subjects with symptomatic bacteriuria (13). Recently, $6 \%$ of bacteriuria more than $100,000 / \mathrm{mm}^{3}$ has been found in a randomly selected subset of 33 diabetic patients. These subjects, aged more than 60 years, were not excluded from screening for microalbuminuria (14). Our sample was comprised of younger patients and only those with IDDM. Thus, until the contribution of bacteriuria is clarified, we must perform a clinical as well as a laboratory investigation of urinary tract infection in all urine collections for microalbuminuria determination.

The effect of first morning urine volume on albumin concentration was confirmed in the present study. Univariate analysis demonstrated that no more than $12 \%$ of the variance in first morning urinary albumin concentration could be accounted for by the independent effect of urine volume. We emphasize that this is a correlation of low intensity with a low beta coefficient. We did not find a significant alteration in the level of urinary albumin concentration that would modify the conventional cutoff level of 20 $\mu \mathrm{g} / \mathrm{ml}$ used to predict an albumin excretion rate of more than 20 or $30 \mu \mathrm{g} / \mathrm{min}$ in timed urine collections (3). Therefore, the variability of urinary volume should not result in the misclassification of diabetic patients for screening purposes. Some reports have described the possible influence of volume on albumin concentration in first morning or overnight urine samples $(9,14,15)$ and, although we agree with them, the variability which we have found was minimal and not constant for our patient sample.

In the present study we have confirmed that metabolic control measured by fasting blood glucose and glycosylated hemoglobin on the same morning of urine collection did not influence urinary albumin concentration. Few studies evaluating the influence of metabolic control on urinary albumin concentration during urine collections have been performed. In one study in which insulin was reduced or withdrawn for some days in IDDM patients the mean albumin excretion rate increased $16 \pm 5.7 \mathrm{mg} / 24 \mathrm{~h}$ while urine volume remained constant (16). However, in the day-to-day management of diabetic patients, no influence on the level of urinary albumin excretion by fasting blood glucose or urinary glucose excretion $(17,18)$ during the day of urine collection has been observed. We did not find any difference be- 
tween groups 1 and 2 in fasting blood glucose, $\mathrm{HbA}_{1}$ or urinary volume. Since patients with a mean albumin concentration of more than $20 \mu \mathrm{g} / \mathrm{ml}$ in first morning urine samples have a greater probability of being microalbuminuric (19), we may infer that we did not find any difference between normoand microalbuminuric patients.

The metabolic control performed a few weeks before did not influence the level of urinary albumin concentration as shown by the unchanged levels of $\mathrm{HbA}_{1}$ in the blood samples obtained on two different days. A majority of cross-sectional studies have shown the same results $(17,18,20)$. A crosssectional study involving non-insulin diabetic patients has demonstrated that fasting blood glucose higher than or equal to $160 \mathrm{mg} /$ dl was significantly and independently associated with the development of proteinuria (21). However, the level of metabolic control after diabetes diagnosis was the most important variable for the development of microalbuminuria and macroalbuminuria as many prospective studies have shown $(4,22,23)$.

A mean intraindividual coefficient of variation in urinary albumin concentration of $56 \%$ was observed in the present study. A level between 30 to $50 \%$ has been found in several studies $(11,18,20)$. Thus, urinary volume, fasting glucose or glycosylated hemoglobin alone cannot account for this variability. Probably individual biological variations seem to be the most important factors $(9,11,18,20)$.

In conclusion, the influence of first morning urine volume on urinary albumin concentration is minimal and not constant. Furthermore, the level of day-to-day metabolic and clinical control in IDDM patients, except probably for patients with ketoacidosis, should not contraindicate microalbuminuria screening in a first morning urine sample. This fact is very important for IDDM outpatients attending public hospitals in developing countries where optimal diabetic control may be very difficult to achieve.

\section{Acknowledgment}

We thank Prof. Renan Moritz Varnier Almeida for assistance in the statistical analysis.

\section{References}

1. Andersen AR, Christiansen JS, Andersen JK, Kreiner S \& Deckert T (1983). Diabetic nephropathy in type 1 (insulin-dependent) diabetes: an epidemiological study. Diabetologia, 25: 496-501.

2. Viberti GC, Jarret RJ, Mahmud U, Hill RD, Argyropoulos A \& Keen H (1982). Microalbuminuria as a predictor of clinical nephropathy in insulin dependent diabetes mellitus. Lancet, I: 1430-1432.

3. Mogensen CE, Vestbo E, Poulsen PL, Christiansen C, Damsgaard EM, Eiskjer $\mathrm{H}$, Froland A, Hansen KW, Nielsen S \& Pedersen MM (1995). Microalbuminuria and potential confounders. Diabetes Care, 18: 572-581.

4. Mathiesen ER, Hommel R, Giese R \& Parving HH (1991). Efficacy of captopril in postponing nephropathy in normotensive insulin dependent diabetic patients with microalbuminuria. British Medical Journal, 303: 81-87.
5. Winocour PH, Harland JOE, Millar JP, Laker MF \& Albert I KGMM (1992). Microalbuminuria and associated cardiovascular risk factors in the community. Atherosclerosis, 93: 71-81.

6. Sachett E \& Daneman D (1988). Screening tests to detect microalbuminuria in children with diabetes. Journal of Pediatrics, 112: 744-748.

7. Hutchison AS, O'Reilly J \& Maccuish AC (1988). Albumin excretion rate, albumin concentration and albumin/creatinine ratio compared for screening diabetics for slight albuminuria. Clinical Chemistry, 34: 2019-2021.

8. Wiegmann TB, Chonko AM, Barnard MJ, MacDougall ML, Folscroft J, Stenphenson J, Kyner JL \& Moore WV (1990). Comparison of albumin excretion rate obtained with different times collection. Diabetes Care, 13: 864-871
9. Townsend JC (1986). Urinary albumin ratio and untimed urine specimens. Clinical Chemistry, 32: 2224

10. National Diabetes Data Group (1979). Classification and diagnosis of diabetes mellitus and other categories of glucose intolerance. Diabetes, 28: 1039-1058.

11. Johnston JJ \& Paterson KP (1993). Estimating urinary albumin excretion rate of diabetes patients in clinical practice. Lancet, 306: 493-494.

12. Mathiesen $E R$, Ronn $B$, Storm $B$, Foght $H$ \& Deckert $T$ (1994). The natural course of microalbuminuria in insulin-dependent diabetes: A 10-year prospective study. Diabetic Medicine, 12: 482-487.

13. Damsgaard EM \& Mogensen CE (1986). Microalbuminuria in elderly hyperglycaemia patients and controls. Diabetic Medicine, 3: 430-435. 
14. Connel SJ, Hollis S, Tieszen KL, McMurray JR \& Dornan TL (1993). Gender and the clinical usefulness of the albumin:creatinine ratio. Diabetic Medicine, 11: 32-36.

15. Rowe DJF, Dawnay A \& Watts GF (1990). Microalbuminuria in diabetes mellitus: review and recommendations for the measurement of albumin in urine. Annals of Clinical Biochemistry, 27: 297-312.

16. Parving $H H$, Noer $I$, Deckert $T$, Eurin $P E$, Nielsen SL, Lyngsoe J, Mogensen CE, Rorth M, Svendensen PA, Trap-Jensen J \& Lassen NA (1976). The effect of metabolic regulation on microvascular permeability to small and large molecules in short-term juvenile diabetics. Diabetologia, 12: 161-166.

17. Tomaselli L, Trischitta $V$, Vinci $C$, Frittitta L, Squatrito S \& Vigneri R (1989). Evaluation of albumin excretion rate in overnight versus 24-h urine. Diabetes Care, 12: 585587.
18. Feldt-Rasmussen B, Dinesen B \& Deckert $M$ (1985). Enzyme immuno assay: an improved determination of urinary albumin in diabetics with incipient nephropathy. Scandinavian Journal of Clinical and Laboratory Investigation, 45: 539-544.

19. Cowell CT, Rogers S \& Silink M (1986). First morning urinary albumin concentration is a good predictor of 24-hour urinary albumin excretion in children with type 1 diabetes. Diabetologia, 29: 97-99.

20. Giampetro O, Miccoli R, Clerico A, Palma L, Bertolotto A, Anichini R, Cristofani R \& Navalesi R (1988). Urinary albumin excretion in normal subjects and in diabetic patients measured by a radioimmunoassay: methodological and clinical aspects. Clinical Biochemistry, 21: 63-68.
21. Gross JL, Stein ACR, Beck MO, Fuchs SC, Silveiro SP, Azevedo MJ \& Friedman $R$ (1993). Risk factors for development of proteinuria by type II (non-insulin dependent) diabetic patients. Brazilian Journal of Medical and Biological Research, 26: 1269-1278.

22. Diabetes Control and Complications Tria Research Group (1993). The effect of intensive treatment of diabetes on development and progression of long-term complications in insulin dependent diabetes mellitus. New England Journal of Medicine, 329: 977-986.

23. Reichard $P$, Nilson BY \& Rosenquist $V$ (1993). The effect of long term intensified insulin treatment on the development of microvascular complications of IDDM. New England Journal of Medicine, 329: 304-309. 